University of Nebraska - Lincoln

DigitalCommons@University of Nebraska - Lincoln

\title{
Environmental Contaminant Concentrations in Canada Goose (Branta canadensis) Muscle: Probabilistic Risk Assessment for Human Consumers
}

\author{
Katherine E. Horak \\ USDA/APHIS/WS National Wildlife Research Center, katherine.e.horak@aphis.usda.gov \\ Richard Chipman \\ U.S. Department of Agriculture \\ Lisa Murphy \\ University of Pennsylvania \\ John Johnston \\ U.S. Department of Agriculture
}

Follow this and additional works at: https://digitalcommons.unl.edu/icwdm_usdanwrc

Part of the Life Sciences Commons

Horak, Katherine E.; Chipman, Richard; Murphy, Lisa; and Johnston, John, "Environmental Contaminant Concentrations in Canada Goose (Branta canadensis) Muscle: Probabilistic Risk Assessment for Human Consumers" (2014). USDA National Wildlife Research Center - Staff Publications. 1511.

https://digitalcommons.unl.edu/icwdm_usdanwrc/1511

This Article is brought to you for free and open access by the U.S. Department of Agriculture: Animal and Plant Health Inspection Service at DigitalCommons@University of Nebraska - Lincoln. It has been accepted for inclusion in USDA National Wildlife Research Center - Staff Publications by an authorized administrator of DigitalCommons@University of Nebraska - Lincoln. 


\title{
Research Note
}

\section{Environmental Contaminant Concentrations in Canada Goose (Branta canadensis) Muscle: Probabilistic Risk Assessment for Human Consumers}

\author{
KATHERINE HORAK, ${ }^{*} *$ RICHARD CHIPMAN, ${ }^{2}$ LISA MURPHY, ${ }^{3}$ AND JOHN JOHNSTON ${ }^{4}$ \\ ${ }^{1}$ U.S. Department of Agriculture, Animal and Plant Health Inspection Service, National Wildlife Research Center, Fort Collins, Colorado 80521; \\ ${ }^{2}$ U.S. Department of Agriculture, National Rabies Management Program, Concord, New Hampshire 03301; ${ }^{3}$ Department of Pathobiology, School of \\ Veterinary Medicine, University of Pennsylvania, Kennett Square, Pennsylvania 19348; and ${ }^{4}$ U.S. Department of Agriculture, Food Safety and \\ Inspection Service, Fort Collins, Colorado 80526, USA
}

MS 13-364: Received 4 September 2013/Accepted 27 March 2014

\begin{abstract}
The issue of food insecurity affects millions of people in the United States every year. Often these people rely on soup kitchens, food banks, and shelters for proper meals, and these organizations often depend on donations to meet needs. One of the most limited food resources is meat. To help alleviate this problem, the U.S. Department of Agriculture Wildlife Services donates more than 60 tons of wild game (deer, moose, feral hogs, goats, geese, and ducks) to a variety of charitable organizations each year. Although commercially produced meat routinely undergoes screening for contaminants, potential exposure to environmental contaminants from eating wild game is not well characterized. In this study, the concentration of 17 contaminants of concern in the breast meat of wild geese was examined. These concentrations were then used in a probabilistic model to estimate potential risk associated with consumption of this meat. Based on model predictions, more than $99 \%$ of all adults were below exposure limits for all of the compounds tested. For all consumer age classes modeled, consumption of wild goose meat may expose a small fraction of these populations to levels of lead higher than the recommended exposure limits. Similarly, mercury exposure was predicted to be higher than the recommended limits when the meat was served as steaks. This information about concentrations of contaminants of concern in goose meat and potential exposures associated with meat consumption based on probabilistic models will enable others to make informed decisions about the risks associated with the consumption of wild meat.
\end{abstract}

Environmental contaminants, either naturally occurring or resulting from industrial pollution, are often present in the air, soil, and water. In addition to their potentially adverse effects on immediately exposed organisms, these contaminants may enter the food chain and affect animals that consume those that have been primarily exposed. Therefore, humans may be exposed to environmental contaminants via the consumption of meat from livestock and/or wildlife.

The concentration of contaminants in food has been a major heath concern for decades. Many studies have been conducted on contaminants of concern (COCs) in commercially raised meat. The U.S. Department of Agriculture (USDA) Food Safety and Inspection Service and the U.S. Food and Drug Administration monitor commercially produced poultry and livestock for chemical contaminants. Although this monitoring system ensures the safety of much of the meat consumed in the United States, a large market exists for non-commercially raised meat for human consumption. A recent survey by the U.S. Fish and Wildlife Service revealed that in 20112.6 million people hunted geese for a total of 23 million hunting days (10). Thus, a

\footnotetext{
* Author for correspondence. Tel: 970-266-6168; Fax: 970-266-6157;

E-mail: katherine.e.horak@aphis.usda.gov.
}

large number of people could be exposed to COCs by consuming wild game.

The problem of food insecurity, i.e., limited access to sufficient food due to inadequate money or other resources, is a major social and health issue worldwide. In 2009, 50 million people in the United States were classified as food insecure (4). In 2010, 6.4 million households were classified as having very low food security, i.e., food intake of some family members was reduced due to limited resources (1). Because many people do not have proper food resources, the demand for food assistance is high, often greater than the available donated food supply. Soup kitchens, food pantries, and shelters associated with Feeding America serve on average 5.7 million different people every week, totaling about 37.0 million people per year (5). Serving such high numbers of people puts a strain on the food resources of the assistance centers, which are trying to provide meals and food options that are nutritious and meet USDA guidelines, and recipients of donated food or meals at soup kitchens may have limited access to meat, fresh vegetables, and fruit (8). To close the gap between supply and demand, numerous organizations have been established to link wild game hunters with soup kitchens or food banks in need of donated meat. 
Many states are addressing the issue of food instability and hunger through programs such as "Hunters for the Hungry" and "Sportsmen Against Hunger." These programs strive to provide high quality fresh meat to people in need. During the 2009 to 2010 hunting season, hunters donated more the $2,500,000 \mathrm{lb}(1,135,000 \mathrm{~kg})$ of meat to help feed food insecure people. These donations provided more than 10,000,000 meals that were high in protein, something that is often missing in diets of these populations (7). The USDA Wildlife Services donates more than 60 tons of wild game (deer, moose, feral hogs, goats, geese, and ducks) to a variety of charitable organizations each year. In fiscal year 2007, Wildlife Services donated 148,443 lb $(67,393 \mathrm{~kg})$ of wild meat including $6,443 \mathrm{lb}(2,925 \mathrm{~kg})$ of goose meat from nine Wildlife Services state programs. These donated meals are a vital source of food for many people.

Because no public health entity routinely monitors contaminants in wildlife, the public health risk to consumers of wildlife has not been well characterized. To address this knowledge gap, we (i) assayed environmental contaminants (pesticides, metals, and PCBs) in harvested Canada geese (Branta canadensis) and (ii) assessed the health risk to consumers by comparing Canada geese contaminant concentrations to contaminant concentrations in commercially produced poultry and regulatory guidance levels. Potential COCs were further evaluated via a probabilistic risk assessment. Based on these results, potential risk management strategies were identified. The intent of this study was to provide information about the concentrations of COCs and potential risks associated with the consumption of Canada goose breast meat to enable regulators and others to make informed decisions about meat consumption guidelines.

\section{MATERIALS AND METHODS}

Collection of samples. Canada geese were collected in urban areas in Minnesota, Wisconsin, Washington, DC, Maryland, New Jersey, South Carolina, Virginia, New York, Pennsylvania, Massachusetts, and Rhode Island. All 194 geese were collected by USDA Wildlife Services as part of urban wildlife damage management programs.

Chemical analysis. Elemental analyses were performed by inductively coupled plasma-mass spectroscopy (ICP-MS; Elan 6100 and AS-93 autosampler, Perkin-Elmer, Foster City, CA). Mercury analysis was performed using an atomic absorption spectrometer (AA800, Perkin-Elmer) equipped with a flow injection atomic spectroscopy system (FIAS 400, Perkin-Elmer) and an AS-90 autosampler.

The analytical standards were purchased from SCP (Champlain, NY), trace metal grade acids were obtained from Fisher Scientific (Pittsburg, PA), and gases were of analytical grade. All dilutions were made with in-house deionized water $(\geq 18 \mathrm{MO} / \mathrm{cm})$ obtained from a Millipore (Billerica, MA) water purification system. When the concentration of a COC was less than the method limit of detection (MLOD) a value of half the MLOD was used for further computations and statistical analyses.

The instrument conditions for mercury analysis by cold vapor hydride generation were a wavelength of $253.7 \mathrm{~nm}$ and $0.7-\mathrm{nm}$ slit. A $0.4-\mathrm{g}$ portion of ground sample was digested overnight in a $70^{\circ} \mathrm{C}$ oven with $2 \mathrm{ml}$ of sulfuric acid and $1 \mathrm{ml}$ of nitric acid in a Teflon perfluoroalkoxy vial (Savillex, Eden Prairie, MN). The digested sample was oxidized with a $10 \% \mathrm{KMnO}_{4}$ solution, and the oxidation reaction was quenched with a $12 \%$ solution of hydroxylamine hydrochloride. The sample was then diluted to $100 \mathrm{ml}$ with $30 \% \mathrm{HCl}$ and then analyzed by atomic absorption spectroscopy. A reagent blank, calibration blank, four working calibration standards, and standard reference material (Dorm-2) from the National Research Council of Canada (Ottawa, Ontario, Canada) were analyzed with each run.

The ICP-MS analysis for minerals was operated at a radio frequency power of 1,200 watts with argon gas in the standard mode. A 0.4 -g portion of tissue was digested in $5 \mathrm{ml}$ of $70 \%$ nitric acid in a Teflon perfluoroalkoxy vial overnight in a $70^{\circ} \mathrm{C}$ oven. For the analysis of heavy and nutritional metals, the digested samples were cooled to room temperature, internal standards $\left({ }^{74} \mathrm{Ge},{ }^{115} \mathrm{In},{ }^{89} \mathrm{Y}\right.$, and ${ }^{159} \mathrm{~Tb}$ ) were added at a final concentration of $20 \mathrm{ppb}$, and the samples were diluted with deionized water to a final volume of $10.0 \mathrm{ml}$. A reagent blank, calibration blank, and four working calibration standards were incorporated with each run. The performance of the ICP-MS and the accuracy of the results were monitored by analyzing standard reference materials (1577b) from the National Institute of Standards and Technology (Gaithersburg, MD).

Samples were analyzed for pesticides with an ion trap gas chromatography-mass spectrometry (MS) system (Polaris Q, Thermo Scientific, Waltham, MA) equipped with an HP-5MS column ( + W Scientific, Folsom, CA). Helium was used as the carrier gas at $2 \mathrm{ml} / \mathrm{min}$. The injector temperature was $200^{\circ} \mathrm{C}$, and the detector interface was set at $230^{\circ} \mathrm{C}$. The initial oven temperature of $70^{\circ} \mathrm{C}$ was held for $1 \mathrm{~min}$, ramped at $20^{\circ} \mathrm{C} / \mathrm{min}$ to $290^{\circ} \mathrm{C}$, and held for $8.5 \mathrm{~min}$. The mass analysis was done in full scan mode from 45 to $550 \mathrm{~m} / \mathrm{z}$. One gram of tissue was homogenized with $4 \mathrm{ml}$ of acetonitrile and spiked with $100 \mathrm{ppm}$ of diphenylamine, which was used as a surrogate. The homogenized samples were centrifuged for $8 \mathrm{~min}$ at $1,400 \mathrm{rpm}$, and the organic extract was pipetted into a clean test tube. The residue was reextracted with $4 \mathrm{ml}$ of fresh acetonitrile, vortex mixed, centrifuged, and combined with the first extract. The combined extracts were cleaned with a C-18 solid phase extraction column (Waters, Milford, MA) that contained $1.5 \mathrm{~g}$ of basic alumina. The columns were washed with $4 \mathrm{ml}$ of methanol, $4 \mathrm{ml}$ of water, and $4 \mathrm{ml}$ of acetonitrile before the samples were loaded. The samples were eluted through the column, and then the column was washed with $4 \mathrm{ml}$ of acetonitrile. The combined sample and acetonitrile wash eluants were reduced to $1 \mathrm{ml}$ and filtered before analysis. A matrix-matched spike of caffeine, naphthalene, and strychnine at $10 \mathrm{ppm}$ was analyzed with each batch of samples.

The analysis of organochlorines and polychlorinated biphenyls (PCBs) was conducted on an gas chromatograph (model 6890, Agilent, Santa Clara, CA) equipped with dual electron capture detectors using Restek 50 quantification columns (Restek, Bellefonte, PA) and HP-5MS confirmation columns ( + W Scientific). Helium was used as the carrier gas at $2 \mathrm{ml} / \mathrm{min}$, and nitrogen was the electron capture detector makeup gas at $60 \mathrm{ml} / \mathrm{min}$. The injector temperature was $250^{\circ} \mathrm{C}$, and detectors were set at 300 and $330^{\circ} \mathrm{C}$ for the Restek 50 column and the HP-5MS column, respectively. The initial oven temperature of $130^{\circ} \mathrm{C}$ was held for $4 \mathrm{~min}$, ramped at $10^{\circ} \mathrm{C} / \mathrm{min}$ to $290^{\circ} \mathrm{C}$, and held for $9 \mathrm{~min}$.

One gram of tissue was homogenized with $4 \mathrm{ml}$ of acetonitrile and extracted after addition of $1 \mathrm{ml}$ of internal standard solution containing $250 \mathrm{ppb}$ of deca-chlorobiphenyl and tetrachloro- $m$ xylene. The extract was transferred to a clean tube, and the residue was reextracted with $2 \mathrm{ml}$ of acetonitrile. The extracts were combined, and $5 \mathrm{ml}$ of deionized water saturated with hexane and sodium sulfate was added and extracted with $5 \mathrm{ml}$ of hexane by 
TABLE 1. Average COC residue data for 194 samples of goose breast meat by state and month of collection

\begin{tabular}{|c|c|c|c|c|c|c|c|c|}
\hline State, month & $n$ & $\begin{array}{c}\text { Arsenic } \\
(\mathrm{ppm})\end{array}$ & $\begin{array}{l}\text { Cadmium } \\
\text { (ppm) }\end{array}$ & $\begin{array}{c}\text { Calcium } \\
\text { (ppm) }\end{array}$ & $\begin{array}{l}\text { Cobalt } \\
(\mathrm{ppm})\end{array}$ & $\begin{array}{c}\text { Copper } \\
\text { (ppm) }\end{array}$ & $\begin{array}{l}\text { Iron } \\
(\mathrm{ppm})\end{array}$ & $\begin{array}{l}\text { Lead } \\
(\mathrm{ppm})\end{array}$ \\
\hline Minnesota, June & 10 & $<$ MLOD & $<$ MLOD & $52.7 \pm 6.342$ & $<$ MLOD & $6.455 \pm 1.715$ & $88.09 \pm 12.359$ & $0.057 \pm 0.021$ \\
\hline Minnesota, July & 10 & $<$ MLOD & $<$ MLOD & $42.7 \pm 5.974$ & $<$ MLOD & $6.482 \pm 2.00$ & $90.8 \pm 15.483$ & $<$ MLOD \\
\hline Wisconsin, June & 10 & $<$ MLOD & $<$ MLOD & $63.0 \pm 9.22$ & $0.018 \pm 0.008$ & $6.949 \pm 1.131$ & $92.35 \pm 14.979$ & $0.932 \pm 2.014$ \\
\hline Wisconsin, July & 10 & $<$ MLOD & $<$ MLOD & $57.27 \pm 24.456$ & $<$ MLOD & $6.82 \pm 1.661$ & $91.33 \pm 17.145$ & $<$ MLOD \\
\hline Washington, June & 10 & $<$ MLOD & $<$ MLOD & $53.51 \pm 6.718$ & $<$ MLOD & $6.682 \pm 2.763$ & $78.49 \pm 26.078$ & $0.051 \pm 0.002$ \\
\hline Washington, July & 10 & $<$ MLOD & $<$ MLOD & $46.37 \pm 4.523$ & $<$ MLOD & $5.283 \pm 1.82$ & $80.68 \pm 19.273$ & $<$ MLOD \\
\hline Maryland, June & 10 & $<$ MLOD & $<$ MLOD & $54.88 \pm 8.23$ & $<$ MLOD & $6.465 \pm 2.021$ & $71.79 \pm 14.733$ & $<$ MLOD \\
\hline Maryland, July & 10 & $<$ MLOD & $<$ MLOD & $46.59 \pm 7.171$ & $<$ MLOD & $5.791 \pm 2.017$ & $59.77 \pm 22.302$ & $<$ MLOD \\
\hline New Jersey, June & 10 & $<$ MLOD & $<$ MLOD & $48.08 \pm 3.776$ & $0.056 \pm 0.128$ & $9.37 \pm 2$ & $98.58 \pm 21.236$ & $<$ MLOD \\
\hline New Jersey, July & 9 & $<$ MLOD & $0.017 \pm 0.005$ & $41.144 \pm 3.219$ & $<$ MLOD & $6.87 \pm 1.321$ & $74.767 \pm 14.199$ & $<$ MLOD \\
\hline South Carolina, June & 10 & $<$ MLOD & $<$ MLOD & $43.69 \pm 2.602$ & $<$ MLOD & $8.586 \pm 1.994$ & $92.69 \pm 7.368$ & $<$ MLOD \\
\hline South Carolina, July & 10 & $<$ MLOD & $<$ MLOD & $43.59 \pm 5.009$ & $0.21 \pm 0.615$ & $8.214 \pm 3.604$ & $78.24 \pm 28.794$ & $<$ MLOD \\
\hline Virginia, June & 10 & $<$ MLOD & $<$ MLOD & $43.84 \pm 3.506$ & $0.017 \pm 0.006$ & $34.703 \pm 85.143$ & $84.36 \pm 10.861$ & $1.855 \pm 5.708$ \\
\hline Virginia, July & 10 & $<$ MLOD & $<$ MLOD & $30.91 \pm 2.984$ & $<$ MLOD & $5.29 \pm 1.118$ & $64.03 \pm 11.134$ & $<$ MLOD \\
\hline New York, June & 10 & $<$ MLOD & $0.017 \pm 0.005$ & $44.03 \pm 4.097$ & $<$ MLOD & $8.333 \pm 2.977$ & $90.74 \pm 8.118$ & $0.087 \pm 0.096$ \\
\hline New York, July & 10 & $<$ MLOD & $0.019 \pm 0.008$ & $40.22 \pm 4.614$ & $<$ MLOD & $7.008 \pm 1.91$ & $74.21 \pm 13.532$ & $<$ MLOD \\
\hline Pennsylvania, June & 10 & $<$ MLOD & $0.024 \pm 0.016$ & $50.92 \pm 2.482$ & $0.019 \pm 0.014$ & $5.729 \pm 2.331$ & $82.37 \pm 13.059$ & $0.056 \pm 0.018$ \\
\hline Pennsylvania, July & 8 & $<$ MLOD & $<$ MLOD & $28.713 \pm 4.892$ & $<$ MLOD & $7.498 \pm 1.457$ & $85.925 \pm 13.276$ & $<$ MLOD \\
\hline Massachusetts, June & 8 & $<$ MLOD & $0.021 \pm 0.012$ & $50.05 \pm 3.712$ & $<$ MLOD & $5.214 \pm 1.724$ & $45.71 \pm 27.739$ & $<$ MLOD \\
\hline , July & 3 & $<$ MLOD & $<$ MLOD & $33.867 \pm 3.782$ & $<$ MLOD & $6.333 \pm 1.297$ & $69.2 \pm 10.233$ & $<$ MLOD \\
\hline Rhode Island, June & 2 & $<$ MLOD & $0.047 \pm 0.045$ & $46.75 \pm 4.313$ & $<$ MLOD & $5.79 \pm 0.24$ & $67.80 \pm 30.688$ & $<$ MLOD \\
\hline Rhode Island, July & 4 & $<$ MLOD & $<$ MLOD & $32.925 \pm 0.971$ & $<$ MLOD & $4.488 \pm 1.525$ & $48.80 \pm 8.879$ & $<$ MLOD \\
\hline
\end{tabular}

${ }^{a} \mathrm{Hg}-\mathrm{aa}$.

shaking on a platform shaker for $12 \mathrm{~min}$ at $200 \mathrm{rpm}$. After gentle centrifugation, the upper hexane layer was transferred to a clean test tube containing $1 \mathrm{~g}$ of sodium sulfate. The extraction was repeated with an additional $5 \mathrm{ml}$ of hexane, and this fraction was combined with the first fraction and cleaned using a Florisil solid phase extraction column loaded with $1.5 \mathrm{~g}$ of sodium sulfate and prewashed with $6 \mathrm{ml}$ of hexane. The samples were eluted through the column and extracted with an additional $4 \mathrm{ml}$ of 35:65 methylene chloride-hexane. Both fractions were combined, reduced to dryness, reconstituted with $1 \mathrm{ml}$ of methanol, filtered, and analyzed. A calibration curve with tetrachloro- $m$-xylene as the internal standard was created with standards for organochlorine at 25 to 2,000 ppb and for PCBs at 100 to 5,000 ppb. Matrix-matched spikes at MLODs were included with each analysis.

Statistical analysis. Residue data from the 194 goose breast muscle samples were analyzed with Excel (Microsoft, Redmond, WA). For computations and statistical analyses, residues values less than the MLOD were assigned a value of half the MLOD (9). The software was used to determine the 50th, 90th, 95th, and 99th percentiles of residue concentration for each COC. Excel was also used to calculate the standard deviations and standard errors of the mean.

Risk assessment. Human consumption of turkey was used as a surrogate for goose meat consumption to perform the human risk analysis for consumption of goose meat. Human turkey consumption data were obtained from "What We Eat in America" of the USDA National Health and Nutrition Examination Survey (NHANES 2003 through 2006) database (3). Exposure limits for the compounds of interest were obtained from published reports from the Agency for Toxic Substances and Disease Registry for arsenic, cadmium, cobalt, DDT, and mercury, the U.S. Environmental Protection Agency for molybdenum and thallium, the National Academy of Sciences dietary reference intakes (assuming values for an 80-kg person) for calcium, copper, iron, magnesium, manganese, selenium, and zinc, and the U.S. Environmental Protection Agency (EPA) integrated risk information system for Aroclor.

Human exposure levels for these COCs were calculated by multiplying the breast tissue residue concentration of the individual compounds by the turkey consumption values: exposure = chemical concentration $\times$ consumption. This product was then divided by the recommended maximum exposure for the individual compounds to give the risk quotient: risk quotient $=$ exposure/ recommended maximum exposure. To calculate the risk quotient of consuming meat three times per week, the breast tissue residue concentration was multiplied by the turkey consumption value. That product was divided by seven times the recommended maximum exposure for each compound. Exposures were estimated using both the average residue concentrations and the maximum observed residue concentration to mimic different meat preparation methods (steaks and ground muscle). Multiple turkey consumption levels also were used to account for the variations in eating habits among the human population.

For this screening of exposure risk of COCs, risk quotients were used to identify compounds that may represent an exposure risk and therefore warrant further investigation. Compounds with risk quotients $\geq 0.75$ were selected for further analysis using probabilistic modeling.

Probabilistic model. Human health risks associated with the consumption of wild goose meat was estimated using probabilistic models generated with Crystal Ball (Oracle Software, Redwood Shores, CA). The model estimated exposure by Monte Carlo sampling from log-normal distributions of residue concentrations derived from the observed residue concentrations and turkey consumption distributions derived from NHANES 2003 through 2006 database. To generate exposure estimates, the model 
TABLE 1. Extended

\begin{tabular}{|c|c|c|c|c|c|c|c|c|}
\hline $\begin{array}{l}\text { Magnesium } \\
\quad(\mathrm{ppm})\end{array}$ & $\begin{array}{l}\text { Manganese } \\
\quad(\mathrm{ppm})\end{array}$ & $\begin{array}{l}\text { Molybdenum } \\
\quad(\mathrm{ppm})\end{array}$ & $\begin{array}{c}\text { Selenium } \\
(\mathrm{ppm})\end{array}$ & $\begin{array}{c}\text { Thallium } \\
\text { (ppm) }\end{array}$ & $\begin{array}{l}\text { Zinc } \\
(\mathrm{ppm})\end{array}$ & $\begin{array}{l}\text { Mercury } \\
(\mathrm{ppm})^{a}\end{array}$ & $\begin{array}{c}\text { Organochlorines } \\
\quad(\mathrm{ppb})\end{array}$ & $\begin{array}{l}\text { PCB } \\
(\mathrm{ppb})\end{array}$ \\
\hline $279.1 \pm 10.461$ & $337 \pm 0.35$ & $0.020 \pm 0.009$ & $259 \pm 0.062$ & $<$ MLOD & $11.804 \pm 1.083$ & $<$ MLOD & $<$ MLOD & $<$ MLOD \\
\hline $276.1 \pm 10.785$ & $250 \pm 0.149$ & $0.020 \pm 0.012$ & $425 \pm 0.134$ & $<$ MLOD & $12.760 \pm 2.512$ & $<$ MLOD & $<$ MLOD & $<$ MLOD \\
\hline $272.6 \pm 11.128$ & $0.416 \pm 0.53$ & $0.021 \pm 0.009$ & $0.389 \pm 0.159$ & $<$ MLOD & $14.624 \pm 4.732$ & $<$ MLOD & $<$ MLOD & $<$ MLOD \\
\hline $270 \pm 11.075$ & $0.271 \pm 0.164$ & $0.022 \pm 0.013$ & $0.448 \pm 0.108$ & $<$ MLOD & $13.861 \pm 2.83$ & $<$ MLOD & $<$ MLOD & $<$ MLOD \\
\hline $260.1 \pm 23.586$ & $0.297 \pm 0.144$ & $0.019 \pm 0.007$ & $0.163 \pm 0.108$ & $<$ MLOD & $13.148 \pm 1.814$ & $<$ MLOD & MLOD & $<$ MLOD \\
\hline $289.3 \pm 15.628$ & $0.224 \pm 0.124$ & $0.018 \pm 0.009$ & $0.321 \pm 0.131$ & $1<$ MLOD & $12.546 \pm 3.027$ & $<$ MLOD & $<$ MLOD & $<$ MLOD \\
\hline $277.2 \pm 14.528$ & $0.2092 \pm 0$ & $0.0192 \pm 0$ & $0.2761 \pm 0.064$ & $<$ MLOD & $15.14 \pm 2.793$ & $<$ MLOD & $<\mathrm{Ml}$ & $<$ MLOD \\
\hline $281 \pm 3$ & & & & $<$ MLOD & $12.412 \pm 1.975$ & $<$ MLOD & $<$ MLOD & $<$ MLOD \\
\hline $279.8 \pm 8.6$ & $0.376 \pm 0.241$ & $0.037 \pm 0.014$ & $4 \pm 0.095$ & & $16.48 \pm 2.973$ & & $<$ MLOD 34 & $34.01 \pm 20.148$ \\
\hline $270.111 \pm 10.006$ & $50 \pm$ & $0.022 \pm 0.014$ & $24 \pm 0$ & $<$ MLOD & $13.264 \pm 2$ & $<$ MLOD & $13.578 \pm 10.733$ & $3<$ MLOD \\
\hline $259.5 \pm 17.309$ & $0.565 \pm 0.119$ & $<$ MLOD & $0.372 \pm 0.117$ & $<$ MLOD & $15.86 \pm 2.036$ & $<$ MLOD & $<$ MLOD & $<$ MLOD \\
\hline $251.8 \pm 25.001$ & $0.15 \pm 0$ & $<$ MLOD & $0.363 \pm 0.113$ & $<$ MLOD & $15.59 \pm 3.53$ & $<$ MLOD & $<$ MLOD & $<$ MLOD \\
\hline $253.1 \pm 10.661$ & $0.539 \pm 0.175$ & $0.017 \pm 0.007$ & $0.287 \pm 0.05$ & $<$ MLOD & $16.45 \pm 4.922$ & $<$ MLOD & $<$ MLOD & $<$ MLOD \\
\hline $230.1 \pm 16.743$ & $0.197 \pm 0.101$ & $0.022 \pm 0.011$ & $0.361 \pm 0.076$ & $<$ MLOD & $11.506 \pm 1.994$ & $<$ MLOD & $11.59 \pm 5.028$ & $<$ MLOD \\
\hline $273.3 \pm 16.984$ & $0.271 \pm 0$ & $0.022 \pm 0.009$ & & $<$ MLOD & $14.18 \pm$ & & MLOD & $37 \pm 37.947$ \\
\hline $265.3 \pm 10.22$ & $0.166 \pm$ & $<$ MLOD & $0.711 \pm$ & $<$ MLOD & $12.133 \pm$ & $<$ MLOD & $<$ MLOD & $73.3 \pm 84.765$ \\
\hline $265.2 \pm 12.865$ & $0.459 \pm 0.113$ & $<$ MLOD & $0.303=$ & $<$ MLOD & $11.566 \pm 2.737$ & $<$ MLOD & $<$ MLOD 4 & $48.6 \pm 55.887$ \\
\hline $258.25 \pm 15.36$ & $0.15 \pm 0$ & $<$ MLOD & $0.343 \pm 0.097$ & $<$ MLOD & $12.384 \pm 2.225$ & $<$ MLOD & $<$ MLOD & $<$ MLOD \\
\hline $258.125 \pm 13.109$ & $0.442 \pm 0.089$ & $0.022 \pm 0.01$ & $0.207 \pm 0.106$ & $<$ MLOD & $13.038 \pm 2.296$ & $<$ MLOD & $<$ MLOD & $<$ MLOD \\
\hline $257 \pm 23.431$ & $0.15 \pm 0$ & $0.04 \pm 0.011$ & $0.317 \pm 0.092$ & $<$ MLOD & $14.8 \pm 3.439$ & $<$ MLOD & $<$ MLOD & $<$ MLOD \\
\hline $252.5 \pm 3.536$ & $0.484 \pm 0.1$ & $<$ MLOD & $<$ MLOD & $<$ MLOD & $13.755 \pm 6.71$ & $<$ MLOD & $<$ MLOD & $<$ MLOD \\
\hline $243.5 \pm 3.317$ & $0.15 \pm 0$ & $<$ MLOD & $0.281 \pm 0.131$ & $<$ MLOD & $11.55 \pm 1.89$ & $0.327 \pm 0.127$ & $<$ MLOD & $<$ MLOD \\
\hline
\end{tabular}

randomly sampled $1,000,000$ times from these probability distributions of contaminant concentration and poultry consumption. Each iteration of the model calculated the daily COC exposure by multiplying the Monte Carlo sampled consumption and residue concentration values. These exposure levels were then compared with the exposure limits to determine the percentage of the population that would exceed the exposure limit for the selected compounds.

Three consumption scenarios were modeled using the Crystal Ball software: scenario 1, daily consumption of wild goose breast steaks; scenario 2, consumption of wild goose breast steaks three times per week; and scenario 3, daily consumption of ground turkey breast. Exposure estimates for scenarios 1 and 2 utilized the entire distribution of residue concentrations. Exposure estimates for scenario 3 were based on the mean residue concentrations for each COC. For scenarios 1 and 3, single day exposure estimates were compared with single day exposure levels of concern. For exposure scenario 2, exposure estimates for three consumption days were compared with 7-day exposure levels of concern.

\section{RESULTS}

Breast meat was analyzed from 194 Canada geese collected in June and July from 11 states in 2006 and 2007. The meat was tested for residue concentrations of the COCs arsenic, cadmium, calcium, cobalt, copper, iron, lead, magnesium, manganese, mercury, molybdenum, selenium, thallium, zinc, organic chemicals, dichlorodiphenyldichloroethylene, and PCBs. In all samples, the residue concentrations of arsenic and thallium were below the MLOD of 0.1 and $0.2 \mathrm{ppm}$, respectively. Mercury concentrations were below the MLOD in all samples except three from Rhode Island, which had concentrations of $0.341,0.449$, and $0.367 \mathrm{ppm}$. All but five samples had levels of cobalt that were below the MLOD of $0.03 \mathrm{ppm}$. Most goose breasts had residue concentrations of lead that were below the MLOD. Only seven animals had concentrations above $0.1 \mathrm{ppm}$, but one of those had a lead residue of $18 \mathrm{ppm}$. Only two samples had dichlorodiphenyldichloroethylene residue levels above the MLOD of $20 \mathrm{ppb}$.

TABLE 2. Comparison of residue concentrations of COCs in wild-caught Canada goose and commercial turkey meat

\begin{tabular}{|c|c|c|c|c|c|c|c|c|}
\hline Breast meat & $\begin{array}{l}\text { Arsenic } \\
(\mathrm{ppm})\end{array}$ & $\begin{array}{l}\text { Cadmium } \\
(\mathrm{ppm})\end{array}$ & $\begin{array}{l}\text { Calcium } \\
\text { (ppm) }\end{array}$ & $\begin{array}{l}\text { Cobalt } \\
(\mathrm{ppm})\end{array}$ & $\begin{array}{l}\text { Copper } \\
\text { (ppm) }\end{array}$ & $\begin{array}{c}\text { Iron } \\
(\mathrm{ppm})\end{array}$ & $\begin{array}{l}\text { Lead } \\
(\mathrm{ppm})\end{array}$ & $\begin{array}{l}\text { Magnesium } \\
(\mathrm{ppm})\end{array}$ \\
\hline Goose & 0.05 & 0.016 & 46.135 & 0.028 & 8.215 & 79.637 & 0.191 & 266.222 \\
\hline Turkey & 0.04 & 0.005 & 110 & 0.025 & 1.17 & 11.9 & 0.018 & 260 \\
\hline Breast meat & $\begin{array}{c}\text { Manganese } \\
(\mathrm{ppm})\end{array}$ & $\begin{array}{l}\text { Molybdenum } \\
\quad(\mathrm{ppm})\end{array}$ & $\begin{array}{l}\text { Selenium } \\
\text { (ppm) }\end{array}$ & $\begin{array}{l}\text { Thallium } \\
\text { (ppm) }\end{array}$ & $\begin{array}{c}\text { Zinc } \\
(\mathrm{ppm})\end{array}$ & $\begin{array}{l}\text { Mercury } \\
(\mathrm{ppm})^{a}\end{array}$ & $\begin{array}{l}\text { Organochlorines } \\
(\mathrm{ppb})\end{array}$ & $\begin{array}{l}\mathrm{PCB} \\
(\mathrm{ppb})\end{array}$ \\
\hline Goose & 0.301 & 0.02 & 0.347 & 0.1 & 13.616 & 0.154 & 10.25 & 29.789 \\
\hline Turkey & 0.2 & 0.024 & 0.235 & 0.05 & 12.8 & $\mathrm{NA}^{b}$ & NA & NA \\
\hline
\end{tabular}

a Hg-aa.

${ }^{b}$ NA, residue data not available 
TABLE 3. Exposure ratio calculated using maximum consumption by age class and maximum residues

\begin{tabular}{|c|c|c|c|c|c|c|c|c|}
\hline \multirow[b]{2}{*}{ Consumer age } & \multicolumn{8}{|c|}{ Exposure ratio } \\
\hline & Arsenic & Cadmium & Calcium & Cobalt & Copper & Iron & Lead & Magnesium \\
\hline Adult ( $\geq 20 \mathrm{yr}$ ) & 0.04 & 0.00 & 0.02 & 0.85 & 9.59 & 1.15 & 156.65 & 0.31 \\
\hline Youth (12-19 yr) & 0.06 & 0.01 & 0.03 & 1.21 & 13.68 & 1.65 & 223.40 & 0.44 \\
\hline \multirow[t]{2}{*}{ Children (3-12 yr) } & 0.08 & 0.01 & 0.04 & 1.54 & 17.36 & 2.09 & 283.52 & 0.56 \\
\hline & \multicolumn{8}{|c|}{ Exposure ratio } \\
\hline Consumer age & Manganese & Molybdenum & Selenium & Thallium & Zinc & Mercury $^{a}$ & Organochlorines & PCB \\
\hline Adult ( $\geq 20 \mathrm{yr}$ ) & 0.06 & 0.05 & 0.95 & 144.24 & 0.41 & 6.48 & 0.37 & 0.11 \\
\hline Youth (12-19 yr) & 0.08 & 0.07 & 1.36 & 205.71 & 0.59 & 9.24 & 0.52 & 0.16 \\
\hline Children (3-12 yr) & 0.11 & 0.09 & 1.72 & 261.07 & 0.75 & 11.72 & 0.66 & 0.21 \\
\hline
\end{tabular}

${ }^{a} \mathrm{Hg}$-aa.

These samples were from New Jersey and Virginia and had concentrations of 42.2 and $25.9 \mathrm{ppb}$, respectively.

Goose breast meat samples from Virginia had the highest average residue concentration of lead at $1.855 \mathrm{ppm}$; samples from the other 10 states had concentrations ranging from less than the MLOD to $0.932 \mathrm{ppm}$ (Table 1). Differences between states also were noted in the residue concentrations of mercury; Rhode Island samples were the only ones with detectable mercury concentrations. The residue concentrations of iron were highly variable across states ranging from $45.71 \mathrm{ppm}$ in Massachusetts to $98.58 \mathrm{ppm}$ in New Jersey. Only three states, New Jersey, New York, and Pennsylvania, had PCB residue concentrations above the MLOD of $50 \mathrm{ppb}$. The average PCB concentrations were $30 \mathrm{ppm}$ in New Jersey samples, $57 \mathrm{ppm}$ in New York samples, and $38 \mathrm{ppm}$ in Pennsylvania samples.

When compared with published residue concentrations in food for human consumption, the residue levels in the goose meat were similar for most COCs (Table 2). The average concentration of calcium in the goose meat was $46 \mathrm{ppm}$, whereas the published concentration of calcium in turkey breast meat with skin is $110 \mathrm{ppm}$. The average cadmium concentration of the goose samples was more than three times higher than the average reported concentration in turkey breast meat of $0.005 \mathrm{ppm}$. The average lead residue concentration in goose meat of $0.19 \mathrm{ppm}$ was more than 10 -fold higher than that of turkey breast meat; however, $96 \%$ of the tested goose samples had a lead concentration less than the MLOD of $0.1 \mathrm{ppm}$. In the calculation of average lead concentration, half the MLOD (i.e., $0.05 \mathrm{ppm}$ ) was used when concentrations were less than the MLOD. The measured concentration of iron in goose meat was $80 \mathrm{ppm}$, which is more than six times higher than the reported $11.9 \mathrm{ppm}$ average in turkey breast meat. Unlike the residues of lead, iron concentrations in the goose meat were all higher than the $11.9 \mathrm{ppm}$ in turkey meat, but the standard deviation was $21 \mathrm{ppm}$. The average mercury concentration in the tested goose samples was 0.154 , which is less than the MLOD; however, because three goose breast samples had mercury concentrations higher than the MLOD, one half the MLOD was used in subsequent calculations for the samples that had concentrations less than the MLOD.

Exposure ratios for each $\mathrm{COC}$ were calculated by dividing the exposure for that $\mathrm{COC}$ by the recommended

TABLE 4. Percentage of population below exposure limit for COCs according to model predictions

\begin{tabular}{|c|c|c|c|c|c|c|}
\hline Consumption of wild goose meat & Cobalt & Copper & Iron & Lead & Mercury & Selenium \\
\hline \multicolumn{7}{|l|}{ Adult ( $\geq 20$ yr) } \\
\hline Steak & 100 & 100 & 100 & 99.3 & 99.4 & 100 \\
\hline Steak $3 \times / w k$ & 100 & 100 & 100 & 99.6 & 99.9 & 100 \\
\hline Ground meat & 100 & 100 & 100 & 99.2 & 99.8 & 100 \\
\hline Ground meat $3 \times / \mathrm{wk}$ & 100 & 100 & 100 & 99.9 & 100 & 100 \\
\hline \multicolumn{7}{|l|}{ Youth (12-19 yr) } \\
\hline Steak & 99.9 & 99.9 & 99.9 & 99.2 & 99.1 & 99.9 \\
\hline Steak $3 \times / \mathrm{wk}$ & 100 & 100 & 100 & 99.5 & 99.9 & 100 \\
\hline Ground meat & 100 & 100 & 100 & 98.9 & 99.2 & 100 \\
\hline Ground meat $3 \times / \mathrm{wk}$ & 100 & 100 & 100 & 99.7 & 100 & 100 \\
\hline \multicolumn{7}{|l|}{ Children (3-12 yr) } \\
\hline Steak & 99.9 & 99.9 & 99.9 & 99.1 & 98.8 & 99.9 \\
\hline Steak $3 \times / \mathrm{wk}$ & 100 & 100 & 100 & 99.7 & 99.9 & 100 \\
\hline Ground meat & 100 & 100 & 100 & 98.5 & 99.3 & 100 \\
\hline Ground meat $3 \times / \mathrm{wk}$ & 100 & 100 & 100 & 99.5 & 100 & 100 \\
\hline
\end{tabular}



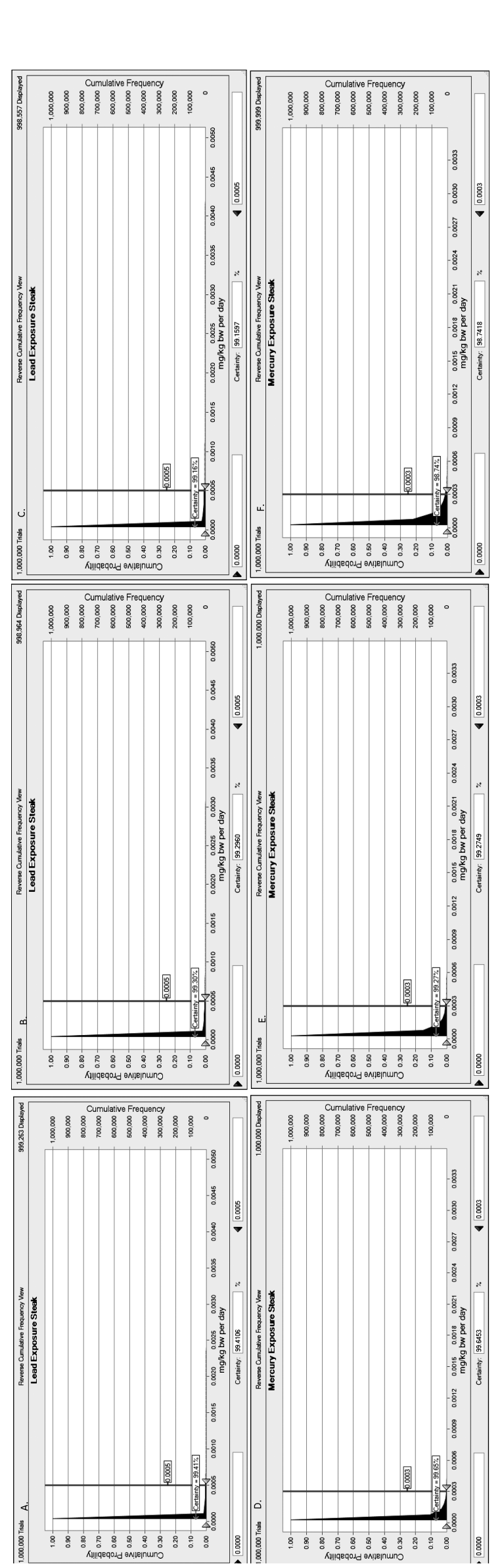

exposure limits (Table 3). For all exposure scenarios, thallium exposure was higher than the recommended limit because the MLOD for thallium is higher than the limit; therefore, even though all samples were below the MLOD, the exposure appears higher than the limit. When the 99th percentile of consumption and the 99th percentile of the concentration for each COC was used, only lead, thallium, and mercury had exposure ratios $>1$, meaning that consumers above the 99th percentile would be exposed to these compounds at higher than the recommended limit. When the exposure ratio was calculated using the maximum consumption and maximum residue concentration, ratios for cobalt, copper, iron, lead, mercury, selenium, and thallium were all $>1$ for all age classes; the exposure ratios for zinc were close enough to 1 that further assessment also was considered warranted. Therefore, a more detailed probabilistic risk analysis for these eight compounds was performed.

More than $99 \%$ of adults were below the exposure limits for the COCs evaluated (Table 4). If goose steaks were consumed once per day, 99.3 and $99.4 \%$ of the population would be below the exposure limit for lead and mercury, respectively. If consumption were limited to three times per week, those values increase to $99.6 \%$ for lead and $99.9 \%$ for mercury. If the goose meat were ground and meat from at least 10 animals were mixed together, 99.2 and $99.8 \%$ of the adult population would be below the exposure limits for lead and mercury, respectively. If consumption of ground meat is limited to three times per week, the models predict that no members of the adult population would exceed the limits for mercury and $99.8 \%$ of adults would be below the exposure limit for lead.

Modeling exposure of youth (ages 12 to 19 years) produced similar results for lead and mercury. If goose steaks were consumed daily, $99.2 \%$ and $99.1 \%$ of youth would be under exposure limits for lead and mercury (Fig. 1). These percentages increased to $99.5 \%$ for lead and 99.9\% for mercury when steaks were consumed only three times per week. When using ground meat from 10 animals mixed together, 98.9 and $99.2 \%$ of youth would not exceed the limits for lead and mercury; if consumption of this meat were limited to three times per week, $100 \%$ of the youth population would be below mercury exposure limits and $99.7 \%$ would be below the lead limits. When consuming goose steaks, $0.1 \%$ of the youth population is predicted to exceed exposure limits for cobalt, copper, iron, and selenium. In all other food consumption scenarios (steak three times per week, ground meat, ground meat three times per week), $100 \%$ of the youth population would be below the exposure limits for these four contaminants.

When consuming goose steaks daily, $0.1 \%$ of children (ages 3 to 12 years) may exceed exposure limits for cobalt, copper, iron, and selenium. Models showed these risks were eliminated when the meat was consumed only three times per week. Like the other age classes, children exceeded exposure limits of both lead and mercury when consuming either steaks or ground meat for either exposure scenario. When consuming steaks, 99.1 and $98.6 \%$ of the children in the population would be under exposure limits for lead and mercury, respectively. If steaks were consumed only three times per week, 99.7 and $99.9 \%$ of the population would be 

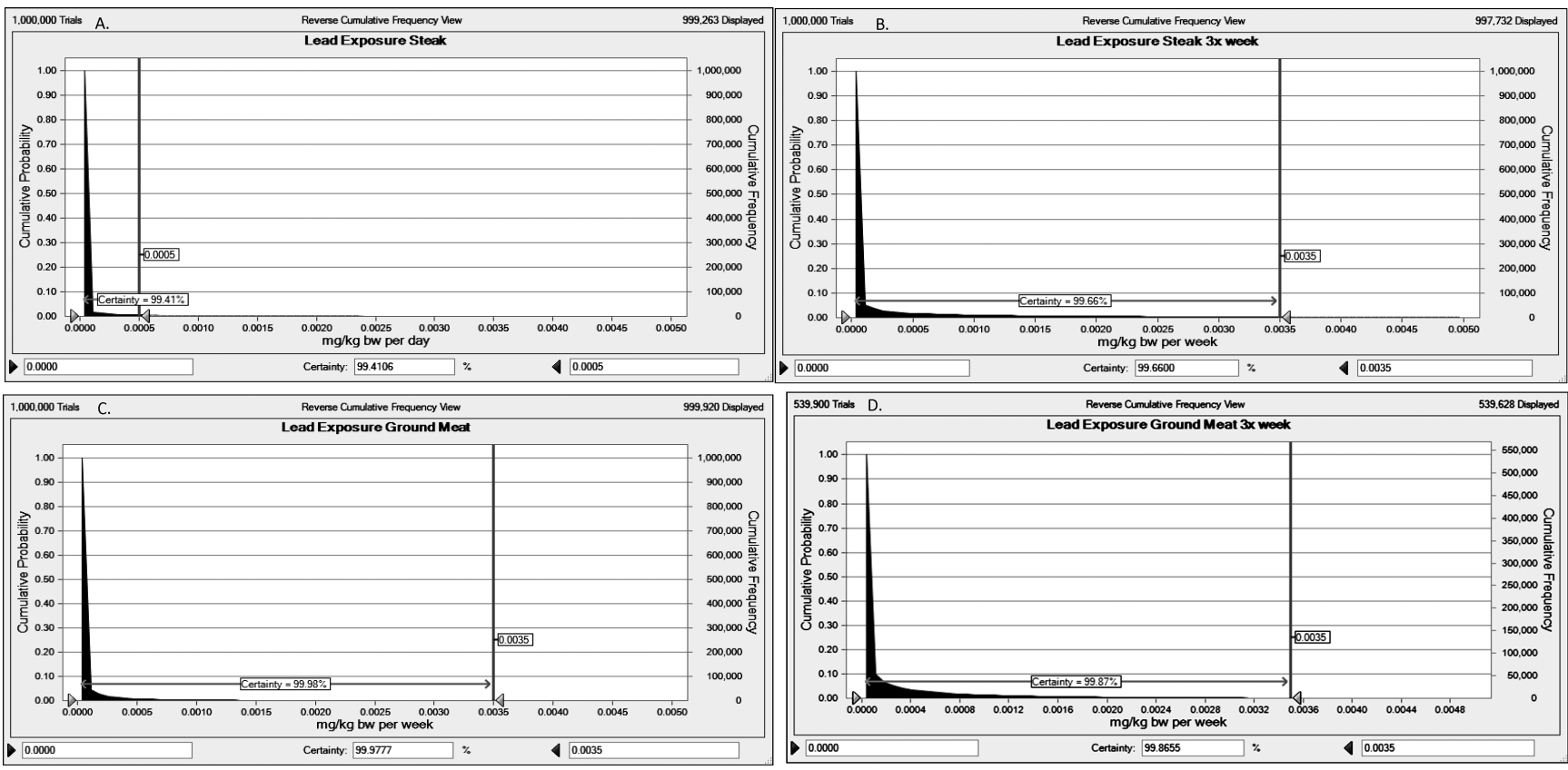

FIGURE 2. Lead exposure resulting from four different meat preparation scenarios. (A) Goose meat served as a steak; (B) goose meat steak served a maximum of three times per week; $(C)$ goose meat from at least 10 animals ground and thoroughly mixed; $(D)$ goose meat from at least 10 animals ground, mixed, and served a maximum of three times per week.

under the limits for lead and mercury, respectively. If goose meat from 10 animals were ground and mixed together, $98.7 \%$ of children consuming this meat would not exceed lead exposure limits. If this ground meat were consumed three times per week, $99.5 \%$ of children would be under the exposure limits for lead (Fig. 2). When consuming this ground meat, $99.3 \%$ of children would be below mercury exposure limits, and if consumption were limited to three times per week models predict that $100 \%$ of children would be below the mercury exposure limits.

\section{DISCUSSION}

For computations and statistical analyses, residues less than the MLOD were assigned a value of half the MLOD. This approach is recommended by the EPA, Office of Pesticide Programs for samples with no detectable residues when it is known or believed that these samples have been treated with a pesticide (9). Because the contaminants investigated in this study are fairly ubiquitous (e.g., legacy pollutants and environmental contaminants), this approach was warranted.

The model estimated exposure by Monte Carlo sampling from log-normal distributions of residue concentrations derived from the observed residue concentrations and turkey consumption distributions derived from the NHANES 2003 through 2006 database. The log-normal distributions from the residue data were used because examination of a wide range of historical biological information and empirical residue measurements indicated that residue data sets are often log-normally distributed (9). Log-normal distributions also are useful for describing contaminants in natural systems because they assume nonnegative values (2). Much empirical evidence exists for a log-normal distribution of pesticides in foods based on a recent study by the United Kingdom's Ministry of Agriculture, Fisheries, and Food (6), in which thousands of individual serving-sized samples were analyzed for a variety of pesticides, and in most cases concentrations followed a log-normal distribution.

The COC residue concentrations in this study did not differ significantly among states. The goose that had the highest concentration of lead, $18.1 \mathrm{ppm}$, was captured in Virginia. This lead concentration was almost three times higher than that found in any other animal. This goose also had the highest measured concentrations of cobalt, copper, and zinc. The trend of animals that have high concentrations of one compound also having high concentrations of others was noted frequently in this data set, which suggests that animals may frequent a relatively limited number of sites containing these COC. Although the number of birds visiting these sites may be low, the concentrations of COCs in their tissues is high enough to necessitate exposure modeling to estimate the risk to humans from consuming this goose meat.

For every age class, consumption of goose steaks was predicted to expose a very small fraction of the population to mercury levels higher than the exposure limits (Fig. 2). In the adult population, $0.7 \%$ of people would exceed the exposure limits from a single meal. This risk decreases if only three meals of goose steak are eaten per week, because the weekly maximum exposure value is seven times the daily recommended maximum exposure and the actual meat consumption is only three times greater than the daily level. The same decrease in risk is true for youth and children. Although these models do predict that some members of the populations will exceed mercury exposure limits, the concentrations of mercury found in the goose breast tissue were considerably 
lower than the U.S. Food and Drug Administration 2011 action level of $1.0 \mathrm{ppm}$ of methylmercury for fish (11). Therefore, it is unlikely that the goose meat would cause any adverse health effects to human consumers.

This survey of wild goose meat indicates that these animals may have quite high concentrations of lead in the muscle tissue, which may pose health concerns if consumed for many meals over long periods of time. Although grinding the goose meat and then mixing meat from numerous animals together will act to dilute the meat from the few animals that may have high lead concentrations, this practice will create a larger quantity of meat that has detectable levels of lead. Which could result in people being exposed to lower concentrations of lead but for potentially multiple meals.

The large demand placed on soup kitchens, food pantries, and shelters to provide nutritious meals often results in these organizations needing additional sources of protein for meals. Donated meat from wildlife agencies constitutes a significant source of protein and is a valuable contribution to the diet of people who rely on meals from these food support organizations. In this study, the concentrations of many environmental COCs were examined in Canada geese that were caught during their migratory molt in suburban areas. The average concentrations of COCs in Canada goose meat were similar to those reported in commercially raised poultry. However, the interanimal variability of in COC concentrations was greater than that observed in commercial poultry. Different types of meat preparation and meal timing can minimize the potential risk of adverse effects due to the consumption of meat from animals with high contaminant concentrations. Meat from numerous animals can be ground together, thereby diluting the possible high contaminant concentration in any one meat sample. To reduce the overall potential exposure to $\mathrm{COCs}$, meals prepared with goose meat can be served only a few times a week. Both of these strategies were modeled in this study, and neither poses a significant risk of exposure to COCs in humans based on the residue concentrations in the geese sampled. The sampled geese were likely nonmigratory and therefore may have been exposed to environmental conditions different from those encountered by migratory birds, resulting in differences in residue COC concentrations. Only 194 geese were analyzed in this study; therefore, the relatively small sample size and their suspected nonmigratory status make inferences from these data to data for migratory birds challenging. Additional studies should be done to determine potential risks to hunters and other populations likely to consume goose meat.

\section{REFERENCES}

1. Coleman-Jensen, A., M. Nord, M. Andrews, and S. Carlson. 2011. Household food security in the United States in 2010. Economic research report. U.S. Department of Agriculture, Economic Research Service, Washington, DC.

2. Cullen, A., and H. C. Frey. 1999. Probabilistic techniques in exposure assessment. Plenum Press, New York.

3. Curtin, L. R., L. K. Mohadjer, S. M. Dohrmann, J. M. Montaquila, D. Kruszon-Moran, L. B. Mirel, M. D. Carroll, R. Hirsch, S. Schober, and C. L. Johnson. 2012. The national health and nutrition examination survey: sample design, 1999-2006. Vital Health Stat. 2(155).

4. Gundersen, C., B. Kreider, and J. Pepper. 2011. The economics of food insecurity in the United States. Appl. Econ. Perspect. Policy 33: 281-303.

5. Mabli, J., R. Cohen, F. Potter, and Z. Zhao. 2010. Hunger in America 2010. Available at: http://feedingamerica.org/hunger-in-america/ hunger-studies/hunger-study-2010/key-findings.aspx. Accessed 10 November 2013.

6. Ministry of Agriculture, Fisheries, and Food. 1997. Pesticides safety directorate. Unit to unit variation of pesticides in fruit and vegetables. Department for Environment, Food and Rural Affairs, London.

7. Robbins, J. 2010. Hunters donate 2.6 million pounds of meat in 2009. Available at: http://www.nrahuntersrights.org/Article.aspx?id=4164. Accessed 10 November 2013.

8. Starkey, L. J. 1994. An evaluation of emergency food bags. J. Can. Diet. Assoc. 55:175.

9. U.S. Enviromental Protection Agency. 2000. Assigning values to non-detected/non-quantified pesticide residues in human health food exposure assessments. U.S. Enviromental Protection Agency, Washington, DC.

10. U.S. Fish and Wildlife Service. 2011. 2011 national survey of fishing, hunting, and wildlife-associated recreation. FHW/11-NAT. U.S. Fish and Wildlife Service and U.S. Census Bureau, Washington, DC.

11. U.S. Food and Drug Administration. 2011. Guidance for industry: action levels for poisonous or deleterious substances in human food and animal feed. Available at: http://www.fda.gov/Food/GuidanceRegulation/ GuidanceDocumentsRegulatoryInformation/ChemicalContaminants MetalsNaturalToxinsPesticides/ucm077969.htm\#merc. Accessed 12 May 2014. 